Research paper

\title{
New times, new trends for ethionamide: In vitro evaluation of drug-loaded thermally carbonized porous silicon microparticles
}

\author{
Nuno Vale ${ }^{\mathrm{a}, *}$, Ermei Mäkilä ${ }^{\mathrm{b}}$, Jarno Salonen ${ }^{\mathrm{b}}$, Paula Gomes ${ }^{\mathrm{a}}$, Jouni Hirvonen ${ }^{\mathrm{c}}$, Hélder A. Santos ${ }^{\mathrm{c}, *}$ \\ ${ }^{a}$ Centro de Investigação em Química da Universidade do Porto, Departamento de Química e Bioquímica, Faculdade de Ciências, Universidade do Porto, Porto, Portugal \\ ${ }^{\mathrm{b}}$ Laboratory of Industrial Physics, Department of Physics and Astronomy, University of Turku, Turku, Finland \\ ${ }^{\mathrm{c}}$ Division of Pharmaceutical Technology, Faculty of Pharmacy, University of Helsinki, Helsinki, Finland
}

\section{A R T I C L E I N F O}

Article history:

Received 28 December 2011

Accepted in revised form 27 February 2012

Available online 6 March 2012

\section{Keywords:}

Caco-2

Drug release

Ethionamide

HepG2

Porous silicon

Metabolism

\begin{abstract}
A B S T R A C T
Multidrug-resistant tuberculosis (MDR-TB) has become a worldwide problem and a major public health concern. The mechanisms of resistance are fairly well characterized for most agents, but MDR limits the therapeutic usefulness of both new and classical medicines against TB. Ethionamide (ETA) is a thioamide antibiotic and one of the most widely used drugs as second line agent for the treatment of MDR-TB. Over the years, some studies have emerged to improve the bioavailability of this drug and of its active metabolites. However, inactive metabolites of ETA are still a major drawback in its application against TB. Porous silicon (PSi) materials can be applied to improve the dissolution behavior of poorly watersoluble compounds and to overcome toxicity and other drug-related problems in oral delivery. In the present work, we have loaded ETA into thermally carbonized-PSi (TCPSi) microparticles and studied the solubility, toxicity, permeability, and metabolic profiles of the PSi-loaded drug. The solubility and permeability of ETA was clearly enhanced after loaded into TCPSi particles at different pH-values. ETA was in general toxic at concentrations above $0.50 \mathrm{mM}$ to HepG2, Caco-2, and RAW macrophage cells, but the toxicity was drastically reduced when the drug was loaded into the microparticles. ETA showed a fast metabolization process in the presence of the TCPSi particles.

In addition, new thiolated metabolites were identified from incubation of ETA-loaded PSi with HepG2 liver cells, which opens new perspectives toward both the understanding of ETA metabolism and the development of novel ETA-based systems with improved efficacy against MDR-TB.
\end{abstract}

(c) 2012 Elsevier B.V. All rights reserved.

\section{Introduction}

Multidrug-resistant tuberculosis (MDR-TB) has become a worldwide problem and a major public health concern. Although the mechanisms of the resistance are fairly well characterized for most agents, namely first line agents, the knowledge of all relevant mechanisms of drug resistance in TB is still limited [1]. One-third of the world's population is currently infected with tuberculosis (TB), and about nine million new cases occur every year [2]. In addition, about two million deaths from TB occur per year, and $\mathrm{TB}$ is also the leading killer infection among individuals infected with HIV. MDR-TB can be classified into three different categories: primary resistance - in individuals originally infected with a resis-

\footnotetext{
* Corresponding authors. Centro de Investigação em Química da Universidade do Porto, Departamento de Química e Bioquímica, Faculdade de Ciências, Universidade do Porto, R. Campo Alegre, 687, P-4169-007 Porto, Portugal. Tel.: +351 2 20402567; fax: +351220402563 (N. Vale), Division of Pharmaceutical Technology, Faculty of Pharmacy, University of Helsinki, P.O. Box 56 (Viikinkaari 5E), FI-00014 Helsinki, Finland. Tel.: +358 9 19159160; fax: +358 919159144 (H.A. Santos).

E-mail addresses: nuno.vale@fc.up.pt (N. Vale), helder.santos@helsinki.fi (H.A. Santos).
}

tant strain of TB; acquired resistance - in individuals originally infected with a susceptible strain that evolves to become resistant to medication; and mixed resistance - when the two aforementioned types of resistance are present $[1,3,4]$.

Ethionamide (ETA, 1 in Fig. 1) is a thioamide antibiotic and one of the most widely used drugs as second line agent for the treatment of MDR-TB. The mode of action of the activated form of ETA is via inhibition of the inhA gene product, enoyl-ACP reductase [5,6]. ETA is activated by a KatG-independent mechanism leading to the formation of an S-oxide metabolite (ETA-SO, 2 in Fig. 1) $[7,8]$. In vivo studies both in mammals and bacteria suggest that ETA-SO retains the biological activity of the parent drug [9], which is in line with the fact that ETA and many current antimycobacterial agents require some form of cellular activation corresponding to the oxidative, reductive, or hydrolytic unmasking of active groups [10-12]. However, other metabolites for ETA (with less therapeutic importance) have been identified, such as ETA-nitrite (2-ethyl-4carboxypyridine), ETA-aldehyde (2-ethyl-4-aldehydopyridine), and ETA-OH (2-ethyl-4-hydroxymethylpyridine) [13-16].

Over the years, some studies have emerged to improve the bioavailability of ETA. For example, the use of gatifloxacin in 


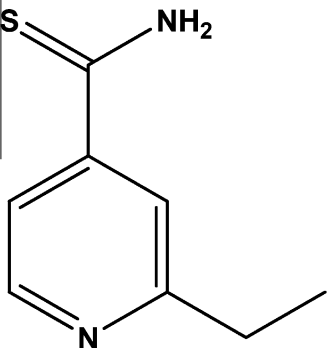

(1)

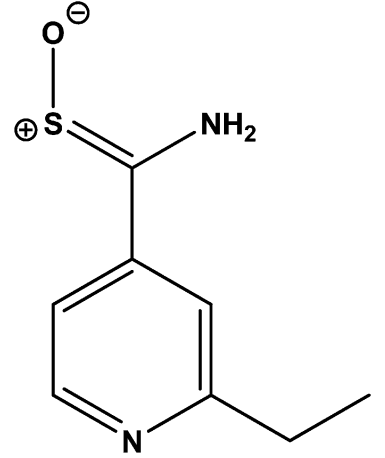

(2)
Fig. 1. Chemical structures of ETA 1 and ETA-SO 2.

combination with ETA with or without pyrazinamide for a 12 week treatment period [17], and the effect of food, orange juice, or anti-acids on the absorption of a single oral $500-\mathrm{mg}$ dose of ETA in healthy volunteers [18] have been tested. Furthermore, pharmacokinetic parameters of ETA following multiple oral doses have also been evaluated [19].

ETA modification or encapsulation has also been studied with the aim of improving the drug's efficacy against MDR-TB. For instance, Cardoso and co-authors synthesized and characterized oxazolinyl and $N$-hydroxyalkyl-ETA derivatives, based on the fact that those groups possess anti-TB activity [20]. ETA was also absorbed into different colloidal systems (nanocapsules and nanospheres), through the alleged formation of a saline bridge between the conjugated acid of ETA and the carboxylate anions of the polymer's outer surface [21].

To the best of our knowledge, porous silicon (PSi) materials have not been tested yet as possible ETA delivery systems. PSi has been used in several biomedical applications ranging from microdevices for therapeutic use [22], chemical and biological sensors [23], to the improvement of the dissolution of poorly watersoluble compounds [24-28]. PSi has also emerged as a versatile material for drug delivery and targeting [29-31], as a drug carrier able to overcome problems associated with oral drugs like toxicity, poor solubility, or sub-optimal pharmacokinetics [30,32]. Furthermore, the PSi surfaces can be easily modified for imaging purposes [33-35], which are biocompatible with multiple cell lines [33-37], and have been shown to efficiently improve delivery of peptides and small interfering RNAs [38-40].

The present work was devoted to study the behavior of ETAloaded PSi microparticles in terms of (a) the dissolution pattern of the loaded drug; (b) cytotoxicity of the drug-loaded particles on human colon carcinoma (Caco-2), human hepatoblastoma (HepG2), and RAW 264.7 murine macrophage cells; (c) drug permeability across biological barriers, using the Caco-2 cell system; and (d) ETA metabolites arising from drug-loaded PSi microparticles incubated with HepG2 cells. Findings are described below and provide new perspectives toward the development of novel approaches for the treatment of MDR-TB.

\section{Materials and methods}

\subsection{Production of the TCPSi microparticles}

The detailed preparation of the particles used has been described elsewhere [25,30,36,41]. Briefly, silicon wafers $\operatorname{Si}\langle 100\rangle$ of $\mathrm{p}^{+}$-type, with resistivity values of $0.008-0.020 \Omega \mathrm{cm}$, were used in the preparation of the thermally carbonized-PSi (TCPSi) microparti- cles. The TCPSi particles were prepared by anodizing the wafers with a current density of $50 \mathrm{~mA} \mathrm{~cm}{ }^{-2}$ in hydrofluoric acid-ethanol mixture (HF:EtOH, 1:1). The process was performed in the dark. Free-standing films were obtained by sharply increasing the current. The free-standing PSi films were ball milled after the anodization. The milled films were dry-sieved with a mesh with nominal pore sizes of 25 and $53 \mu \mathrm{m}$. The milling and sieving cycles were repeated several times to achieve the desired particle sizes. After the dry-sieving, the particles were rinsed with EtOH on the mesh in order to remove small agglomerates. Prior to any surface treatments, the particles were treated with HF to remove the oxides formed during the milling. The particles were dried for $1 \mathrm{~h}$ at $65^{\circ} \mathrm{C}$.

\subsection{Characterization of TCPSi microparticles}

The porous properties of the TCPSi microparticles produced were characterized with $\mathrm{N}_{2}$ adsorption/desorption measurements on a Tristar 3000 (Micromeritics) instrument at $-196{ }^{\circ} \mathrm{C}$. The particle characterization was performed in terms of average pore diameter $(D)$, pore volume $(V)$, and is the specific surface area $\left(A_{s}\right)$. The $D$ values were calculated from the desorption branch using the Barrett-Joyner-Halenda (BJH) theory [42], and $A_{\mathrm{s}}$ and $V$ were calculated from the desorption branch using the Brunauer-EmmettTeller (BET) theory [43].

The surface morphologies of the unloaded and loaded particles were studied by scanning electron microscopy (SEM; Zeiss DSM 962, Carl Zeiss, Oberkochen, Germany). The samples were sputter coated with platinum before the imaging.

\subsection{Loading of ETA into TCPSi microparticles}

Drug loading was performed from an ETA solution in acetone (20 mg/mL) heated to $60^{\circ} \mathrm{C}$ in a water bath. TCPSi microparticles (250 mg) were added into the hot solution of ETA and kept under gentle magnetic stirring for $1 \mathrm{~h}$. The particles were then vacuum filtered from the solution and dried at $65{ }^{\circ} \mathrm{C}$ overnight.

Drug loading was determined by thermogravimetry (TG) on a TGA-7 instrument (Perkin Elmer Inc., MA, USA) with a heating rate of $20^{\circ} \mathrm{C} / \mathrm{min}$ under a synthetic air purge gas flow of $200 \mathrm{~mL} / \mathrm{min}$. TG results indicated a drug loading of approx. $5.4 \mathrm{wt}$.\%. Similar values were also obtained from high-performance liquid chromatography (HPLC) quantification of ETA released from the particles (see further below).

\subsection{ETA release experiments}

Dissolution experiments of pure ETA and ETA-loaded TCPSi microparticles were performed using a modified USP paddle method [44]. Buffer solutions used were $100 \mathrm{~mL}$ of $10 \times$ Hank's buffered salt solution (HBSS) in either $10 \mathrm{mM}$ 2-(N-morpholino)ethanesulfonic acid, MES ( $\mathrm{pH}$ 5.5), or $10 \mathrm{mM}$ 4-(2-hydroxyethyl)-1-piperazineethanesulfonic acid, HEPES (pH 7.4). Pure ETA and drug-loaded TCPSi microparticles were weighed directly into open gelatin capsules. A small magnet was used as a sinker and stirrer inside each capsule, and capsule contents put under stirring at $300 \mathrm{rpm}$ and $37^{\circ} \mathrm{C}$. All the experiments were performed at least in triplicate under sink conditions. Aliquots were collected at given time points for subsequent quantification of the soluble drug by HPLC and the sample volume withdrawn replaced by fresh pre-warmed buffer.

\subsection{Viability tests cell lines and cultures}

The in vitro tests were performed with differentiated and nondifferentiated human colon carcinoma (Caco-2), human hepatoblastoma (HepG2), and RAW 264.7 murine macrophage cells, all 
from the American Type Culture Collection, USA. The cells were cultured in $75 \mathrm{~cm}^{2}$ culture flasks (Corning Inc. Life Sciences, USA) using Dulbecco's modified Eagle's medium (DMEM, EuroClone, S.p.A., Italy) supplemented with $10 \%$ fetal bovine serum (FBS, Gibco, Invitrogen, USA), 1\% non-essential amino acids, $1 \%$ L-glutamine, penicillin $(100 \mathrm{IU} / \mathrm{mL})$, streptomycin $(100 \mu \mathrm{g} / \mathrm{mL})$ (all from Euroclone, S.p.A., Italy), and also $1 \%$ sodium pyruvate (Invitrogen, CA, USA) in the particular case of HepG2 cells.

Cell cultures were maintained at $37{ }^{\circ} \mathrm{C}$ in $5 \% \mathrm{CO}_{2}$ atmosphere and 95\% relative humidity (BB 16 gas incubator, Heraeus Instruments $\mathrm{GmbH}$, Germany). Growth media were changed every other day until the time of use. Prior to each test, the cells were harvested using $0.25 \%$ trypsin (Euroclone S.p.A., Italy) in $0.05 \mathrm{mM}$ ethylenediamine tetraacetic acid (EDTA; Sigma-Aldrich, USA) in phosphate-buffered saline (PBS, Invitrogen, USA) solution and diluted to a density of $2-5 \times 10^{5}$ cells $/ \mathrm{mL}$. Suspended cells were seeded into 6-, 12-, or 96-well plates (PerkinElmer Inc., USA) and incubated for about $24-48$ h to reach confluency.

The number of viable cells in culture was quantified based on the amount of ATP produced by metabolically active cells (CellTiter-Glo ${ }^{\circledR}$ Luminescence Cell Viability Assay, Promega, USA). Cells cultured in 96-well plates, as described above, were washed twice with $100 \mu \mathrm{L}$ of HBSS (pH 7.4). Then, $100 \mu \mathrm{L}$ of pure ETA or ETA-loaded TCPSi suspensions (in HBSS) were added to each well and the plates incubated at $37^{\circ} \mathrm{C}$ for $24 \mathrm{~h}$. After incubation, the wells were washed three times with HBSS to remove excess of pure drug or microparticles, and the plates were equilibrated at room temperature for about $30 \mathrm{~min}$. Then, $100 \mu \mathrm{L}$ of the developing reagent was added to each well, according to manufacturer's instructions, and the resulting luminescence was measured on a Wallac 1450 MicroBeta/Trilux luminescence counter (PerkinElmer Inc., MA, USA). Cell viability was expressed as the percentage of luminescence measured for the negative control (only buffer). Triton X-100 (Sigma-Aldrich, USA) was used as a positive control for cytotoxic activity [36].

\subsection{Caco-2 permeability experiments}

The permeability of pure ETA (control) or ETA-loaded TCPSi microparticles was studied across Caco- 2 cell monolayers. The cells, grown as previously described, were seeded on 12-Transwell ${ }^{\circledR}$ cell culture inserts (polycarbonate membranes, pore size $0.4 \mu \mathrm{m}$, growth area $1.12 \mathrm{~cm}^{2}$, Corning Inc. Life Sciences, USA) to form monolayers that were used 21-28 days after seeding. Cell monolayers were rinsed twice with HBSS $(\mathrm{pH} 7.4)$ and equilibrated in the transport buffers under experimental conditions for $30 \mathrm{~min}$. The permeability of the test samples (pure ETA and ETA-loaded microparticles) was assessed in apical-to-basolateral direction at an apical pH of 5.5 and basolateral $\mathrm{pH}$ of 7.4 , at $37{ }^{\circ} \mathrm{C}$ with orbital shaking $(50 \mathrm{rpm})$. Control experiments (untreated cells) were performed in parallel. Transepithelial electrical resistance (TEER) was measured using a Millicell ERS Voltohmmeter (Millipore Corp., Bedford, MA, USA), and monolayers with TEER values below $250 \Omega \mathrm{cm}^{2}$ were discarded. The apical solution was changed to HBSS to which was added pure ETA (ca. $111 \mu \mathrm{g}$ ) or loaded TCPSi microparticles $(2.0 \mathrm{mg})$. Aliquots $(100 \mu \mathrm{L})$ from the basolateral compartment were collected at given time points for posterior drug quantification by HPLC withdrawn replaced by fresh pre-warmed buffer. Monolayer integrity after each experiment was determined by TEER and allowed confirming that, under the experimental conditions used, Caco-2 monolayers were not damaged (data not shown).

\subsection{Metabolization of ETA in HepG2 cells}

In order to compare the degree of drug metabolization in both pure ETA and ETA-loaded TCPSi microparticles, HepG2 cells, grown as described above, were seeded in 6-well plates (Corning Inc. Life Sciences, USA) or in 12 -Transwell ${ }^{\circledR}$ cell culture inserts, in all cases using HBSS buffer at pH 7.4. Pre-dissolved ETA (control solutions) or ETA-loaded TCPSi microparticles were added to cells. Aliquots $(100 \mu \mathrm{L})$ were collected at different time points, the withdrawn replaced by fresh pre-warmed buffer, and the samples analyzed by LC-EIS/MS as described below.

\subsection{HPLC quantification of ETA}

ETA concentrations in the samples were analyzed by HPLC (Agilent 1100 Series, Agilent Technologies, Germany) using an Agilent G1365B multiple wavelength detector, an Agilent G1367A well-plate autosampler, an Agilent G1316A thermostatted column compartment (at $25^{\circ} \mathrm{C}$ ), an Agilent G1312A binary pump, and an Agilent G1379A microvacuum degasser. Sample volumes of $20 \mu \mathrm{L}$ were injected on a Gemini C18 reversed-phase column (100 $\times$ $4.6 \mathrm{~mm}$; $3 \mu \mathrm{m}$ particle diameter; Phenomenex, USA) and eluted isocratically, using $90 \%$ acetonitrile and $10 \%$ aqueous trifluoroacetic acid $(0.1 \%, \mathrm{pH} 2.0)$ as mobile phase, at a flow rate of $1.0 \mathrm{~mL} /$ min. Volumes of $20 \mu \mathrm{L}$ of the samples were injected for analysis. ETA presented a retention time of 2.9 min under these conditions (detection at $\lambda=220 \mathrm{~nm}$ ).

\section{9. $L C / U V-D A D / E S I-M S^{n}$ analyses}

LC/DAD/ESI-MS ${ }^{n}$ analyses were performed on a Finnigan Surveyor Plus HPLC (Thermo Scientific, USA) instrument equipped with a diode-array detector and a mass detector. The HPLC system consisted of a quaternary pump, an autosampler, a degasser, a photodiode-array detector, and a thermostatted column compartment that was kept at $25^{\circ} \mathrm{C}$. An end-capped Merck Purospher C-18 column $(150 \mathrm{~mm} \times 4 \mathrm{~mm} ; 5 \mu \mathrm{m}$ particle diameter, end-capped) was used and the elution gradient was $0 \% B(0 \mathrm{~min})$ to $100 \% B$ (30 min), with $A=0.1 \%(\mathrm{v} / \mathrm{v})$ aqueous trifluoroacetic acid and $B=$ acetonitrile, both previously degassed and filtered. The column was re-equilibrated for $10 \mathrm{~min}$ between injections.

The mass detector was a Finnigan Surveyor LCQ XP MAX quadruple ion trap mass spectrometer (MS) equipped with an ESI interface. Control and data acquisition was carried out with Xcalibur $^{\circledR}$ software (ThermoFinnigan, San Jose, USA). Nitrogen above 99\% purity was used and the gas pressure was $520 \mathrm{kPa}$ (75 psi). The instrument was operated in positive-ion mode with electrospray ionization (ESI) needle voltage, $5.00 \mathrm{kV}$; ESI capillary temperature was $325^{\circ} \mathrm{C}$; Full scans covered the mass range $m / z$ from 50 to 2000. MS/MS data were simultaneously acquired for the selected precursor ion. Collision-induced dissociation CID-MS/MS experiments were performed using helium as the collision gas with 25-35 eV of energy.

\subsection{Statistical analysis}

Results are given as average \pm standard deviation (SD) from at least three independent experiments. Data were analyzed by Oneway Analysis of Variance (ANOVA), followed by Dunnett's HSD post hoc test. These tests were performed using GraphPad Prism v. 5.01 (GraphPad Software, CA, USA), and the level of significance was set at a probability of ${ }^{*} p<0.05,{ }^{* *} p<0.01$, and ${ }^{* * *} p<0.001$.

\section{Results and discussion}

\subsection{Characterization of TCPSi microparticles}

The physicochemical properties of the TCPSi microparticles used in this study were studied. The particles presented a pore size 


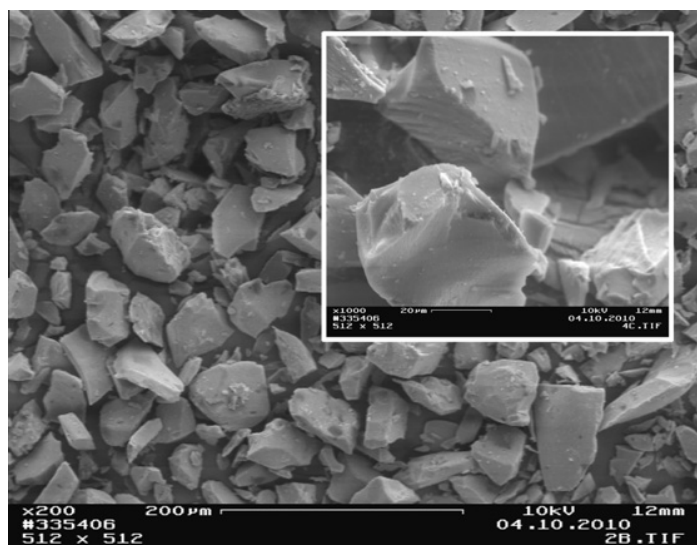

Fig. 2. SEM micrographs of TCPSi microparticles. Scale bars are $200 \mu \mathrm{m}$ and $20 \mu \mathrm{m}$ for the main frame and the inset, respectively.

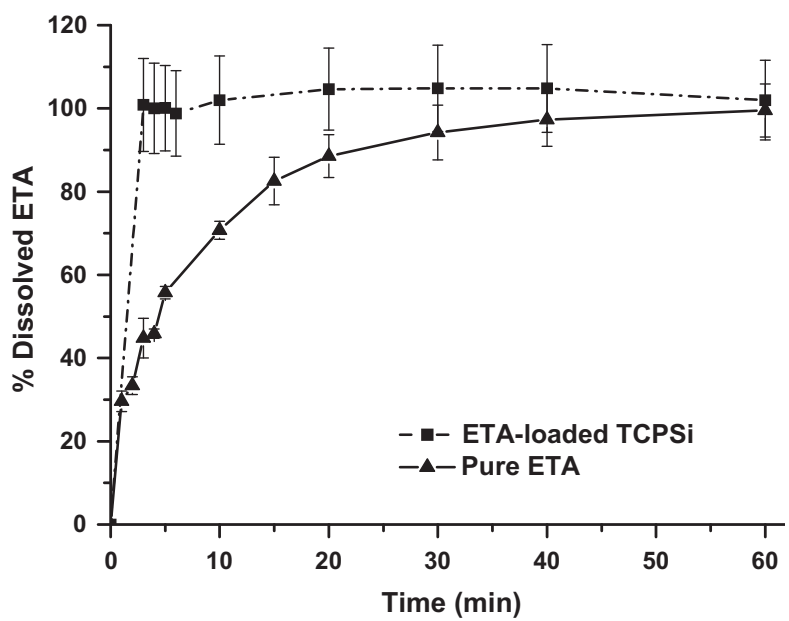

Fig. 3. Release rate of ETA at pH 5.5 (HBSS buffer) and at $37^{\circ} \mathrm{C}$ : ( $\left.\mathbf{\Lambda}\right)$; pure ETA; and (घ) ETA-loaded TCPSi microparticles. Error bars represent means $\pm \operatorname{SD}(n \geqslant 3)$.

of $11.6 \mathrm{~nm}$, a surface porosity of $0.81 \mathrm{~cm}^{3} / \mathrm{g}$, and a specific surface area of $225 \mathrm{~m}^{2} / \mathrm{g}$. Scanning electron microscopy (SEM) analysis of

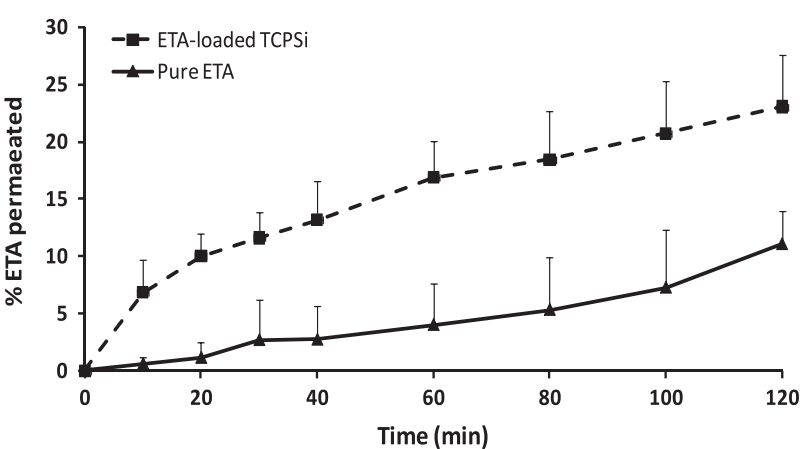

Fig. 5. Permeation profiles at $37^{\circ} \mathrm{C}$ of ( $\left.\boldsymbol{\Delta}\right)$ pure ETA and ( $\left.\boldsymbol{\square}\right)$ ETA-loaded TCPSi microparticles across Caco-2 monolayers, in HBSS buffer at pH 5.5 and 7.4 in the apical and basolateral compartments, respectively. Error bars represent mean \pm SD $(n \geqslant 3)$.

the particles' morphology allowed observing that the PSi particles have an angular structure with a size fraction of $25-53 \mu \mathrm{m}$, as shown in Fig. 2.

\subsection{Physicochemical properties of pure and loaded drug}

The solubility of pure ETA in aqueous buffer at $\mathrm{pH} 1.2$ was $4 \mathrm{mg} /$ $\mathrm{mL}$, but decreased to $741 \mu \mathrm{g} / \mathrm{mL}$ in the $\mathrm{pH}$ range of $5.5-7.4$, which concurs with the weakly basic nature of the drug.

The percentage of ETA released and dissolved over time was measured both for the pure drug and for ETA-loaded TCPSi microparticles, at pH 5.5 and $37^{\circ} \mathrm{C}$, as shown in Fig. 3. Maximal drug dissolution was clearly reached faster when using the drug-loaded TCPSi microparticles, as compared to pure ETA. Similar results were obtained at pH 7.4 (data not shown). For the ETA-loaded TCPSi microparticles, the maximal drug dissolution was reached at 3 and $1 \mathrm{~min}$ for $\mathrm{pH} 5.5$ and 7.4, respectively, whereas for the pure drug, it took 60 and $40 \mathrm{~min}$ for $\mathrm{pH} 5.5$ and 7.4, respectively.

\subsection{Cell viability and ATP production}

Fig. 4A shows the ATP production in RAW 264.7 macrophages, Caco-2, and HepG 2 cells in the presence of different concentrations of pure ETA. As expected, increasing the ETA concentration led to increased toxicity to the different cell lines used. Thus, ETA was
(A)

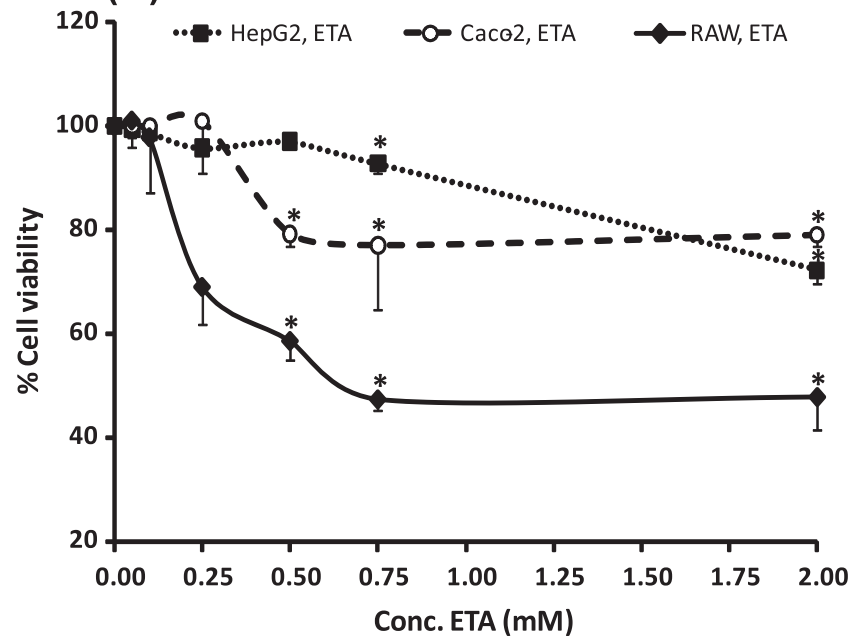

(B)

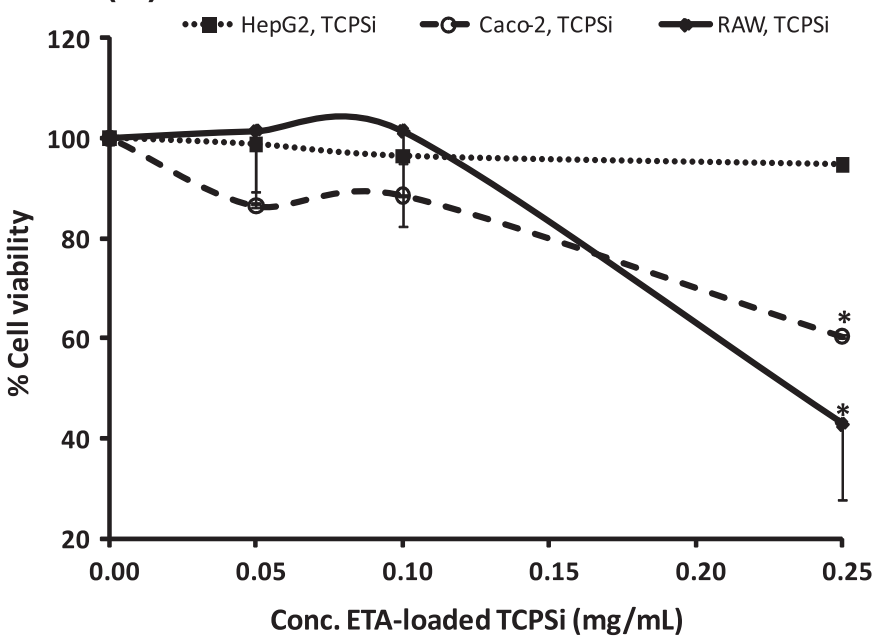

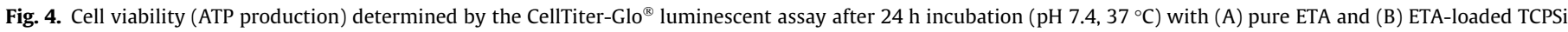
microparticles. Error bars represent mean $\pm \operatorname{SD}(n \geqslant 3) .{ }^{*} p<0.05$, statistically significant differences found compared to the control groups. 
<smiles>CCc1cc(C(=N)S(=O)O)ccn1</smiles>

(3)<smiles>CCc1cc(C(N)=O)ccn1</smiles>

(4)<smiles>CCc1cc(C#N)ccn1</smiles>

(5)

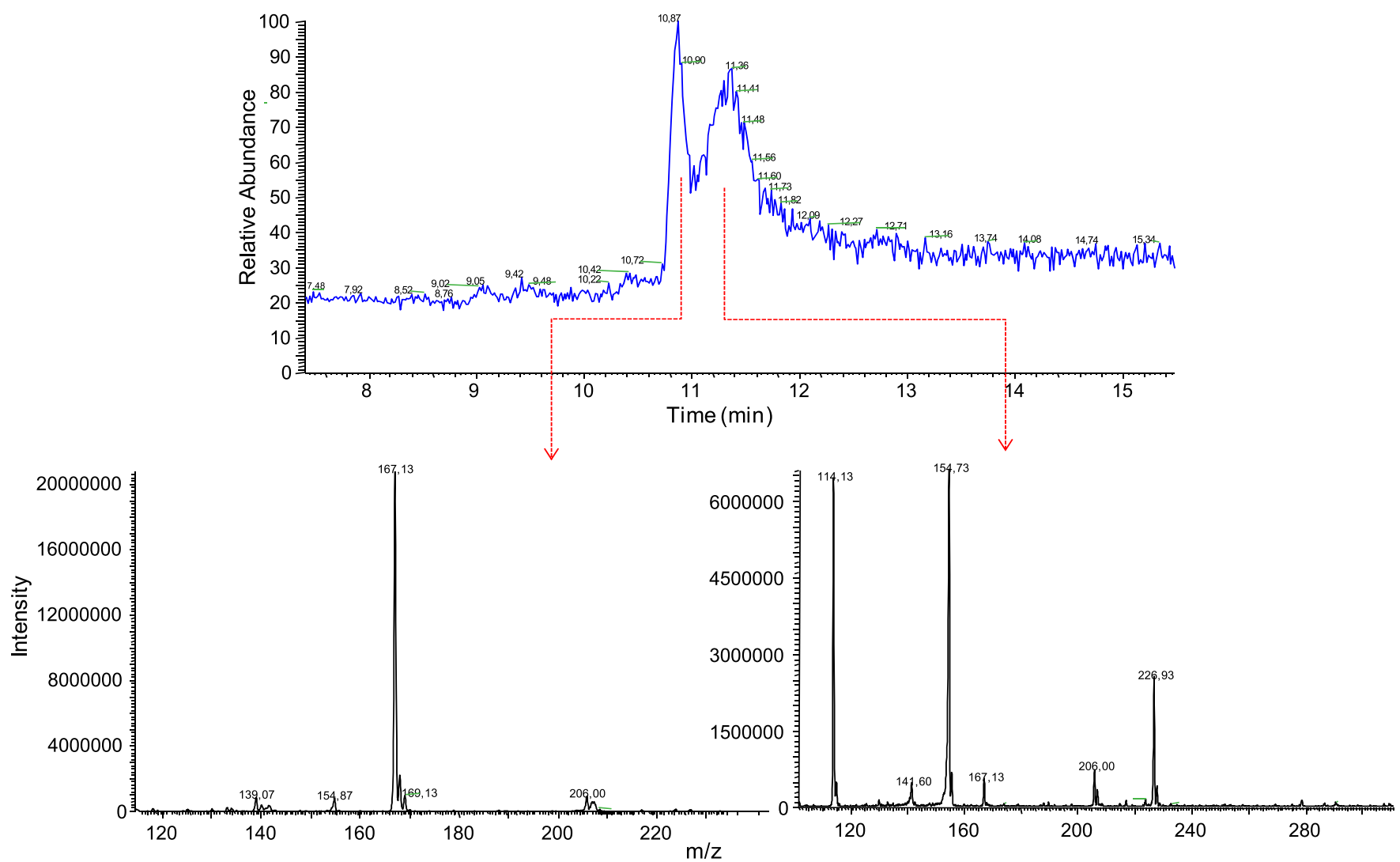

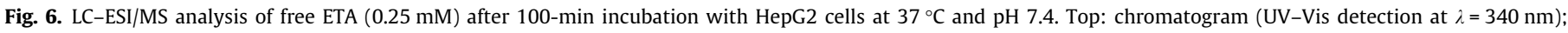

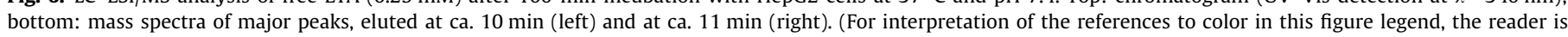
referred to the web version of this article.)

not toxic to RAW 264.7 macrophages and Caco-2 cells at concentrations up to $0.10 \mathrm{mM}$ or $0.25 \mathrm{mM}$, respectively. Interestingly, the concentration threshold was higher in the case of HepG2 cells, to which ETA was non-toxic at concentrations up to $0.75 \mathrm{mM}$.

Fig. 4B shows the ATP production in RAW 264.7 macrophages, Caco-2, and HepG2 cells in the presence of different amounts of ETA-loaded TCPSi microparticles. As in the case of pure drug, also increasing amounts of the TCPSi suspensions led to increased toxicity to the tested cells. Nevertheless, suspensions of ETA-loaded TCPSi microparticles up to $0.15 \mathrm{mg} / \mathrm{mL}$ ( $0.90 \mathrm{mM}$ of ETA) kept viability of both RAW 264.7 macrophages and Caco-2 cells above $80 \%$, while showing no toxicity toward HepG2 cells up to $0.25 \mathrm{mg} / \mathrm{mL}$ (1.5 mM of ETA), which shows a clear improvement on the drug threshold toxicity when loaded to the particles when compared to pure drug only. This is probably because the loaded drug is in a first stage protected by the particles avoiding strong drug-cell interactions reducing the direct exposure of the drug to the cells and thus, reducing significantly the cytotoxicity. In later stages, the drug released from the pores of the particles is fully available for cell interactions leading to an increase in cytotoxicity. Importantly, in either of the above mentioned situations, the drug-cell interactions are minimized somewhat by the presence of the TCPSi particles when compared to pure drug alone, which reduces significantly the drug threshold toxicity.

\subsection{Permeability across Caco-2 monolayers}

Fig. 5 shows the permeability of pure ETA and ETA-loaded TCPSi microparticles across Caco- 2 monolayers. The permeation of ETA was studied both using the pure drug and TCPSi particles loaded with an equal amount of the drug. The permeation of ETA released from the TCPSi particles across Caco-2 cells was faster than that of the pure drug: after $20 \mathrm{~min}$, the permeation of the released drug was already eleven-fold than that of the pure drug. A rough 


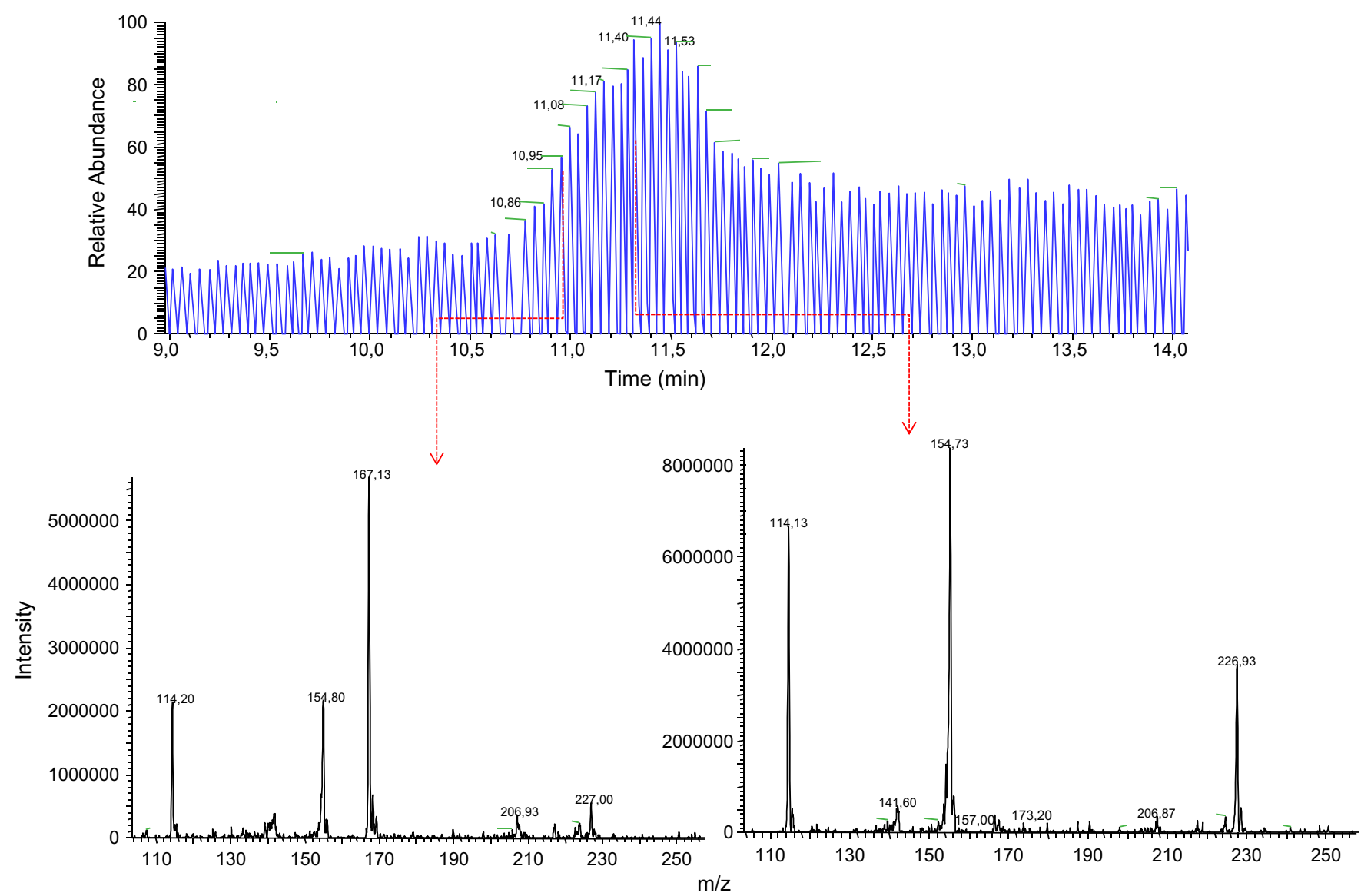

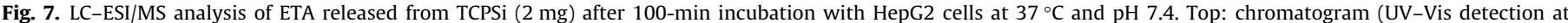

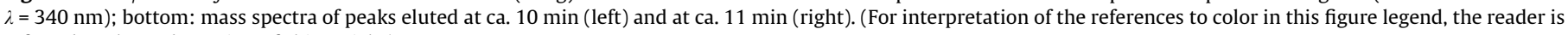
referred to the web version of this article.)

\section{Peak 114}<smiles>O=CC1CCNCC1</smiles>

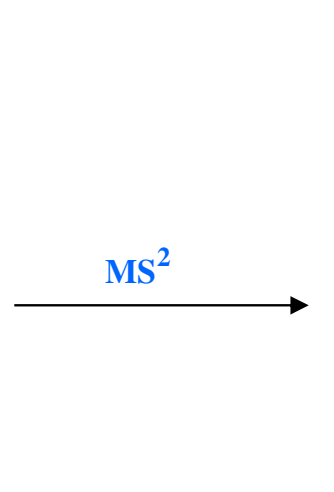

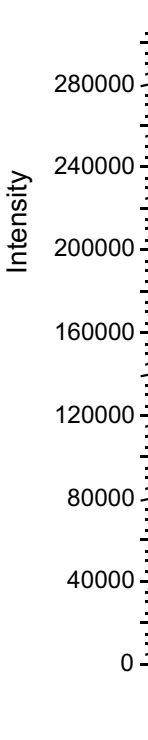
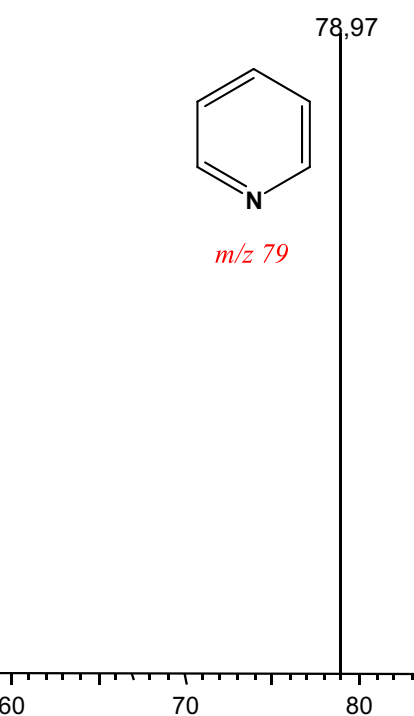

80

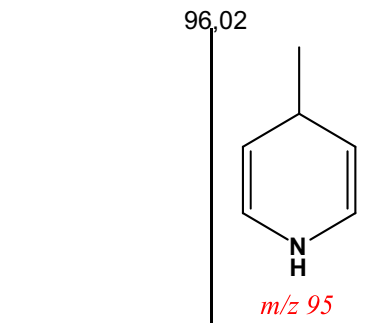

70

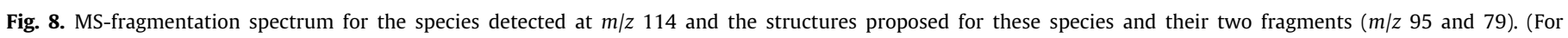
interpretation of the references to color in this figure legend, the reader is referred to the web version of this article.)

calculation of the apparent permeability [45] of ETA gives of $13 \times 10^{-5}$ and $97 \times 10^{-5} \mathrm{~cm} / \mathrm{s}$ for pure ETA and ETA-loaded TCPSi, respectively. This represents more than a seven-fold increase in the apparent permeability of pure ETA across the Caco-2 monolay- ers, when using drug-loaded TCPSi microparticles under the experimental conditions studied. Such increase in ETA permeation is probably due enhanced solubility followed by fast release of the loaded drug. Therefore, use of ETA-loaded TCPSi microparticles 


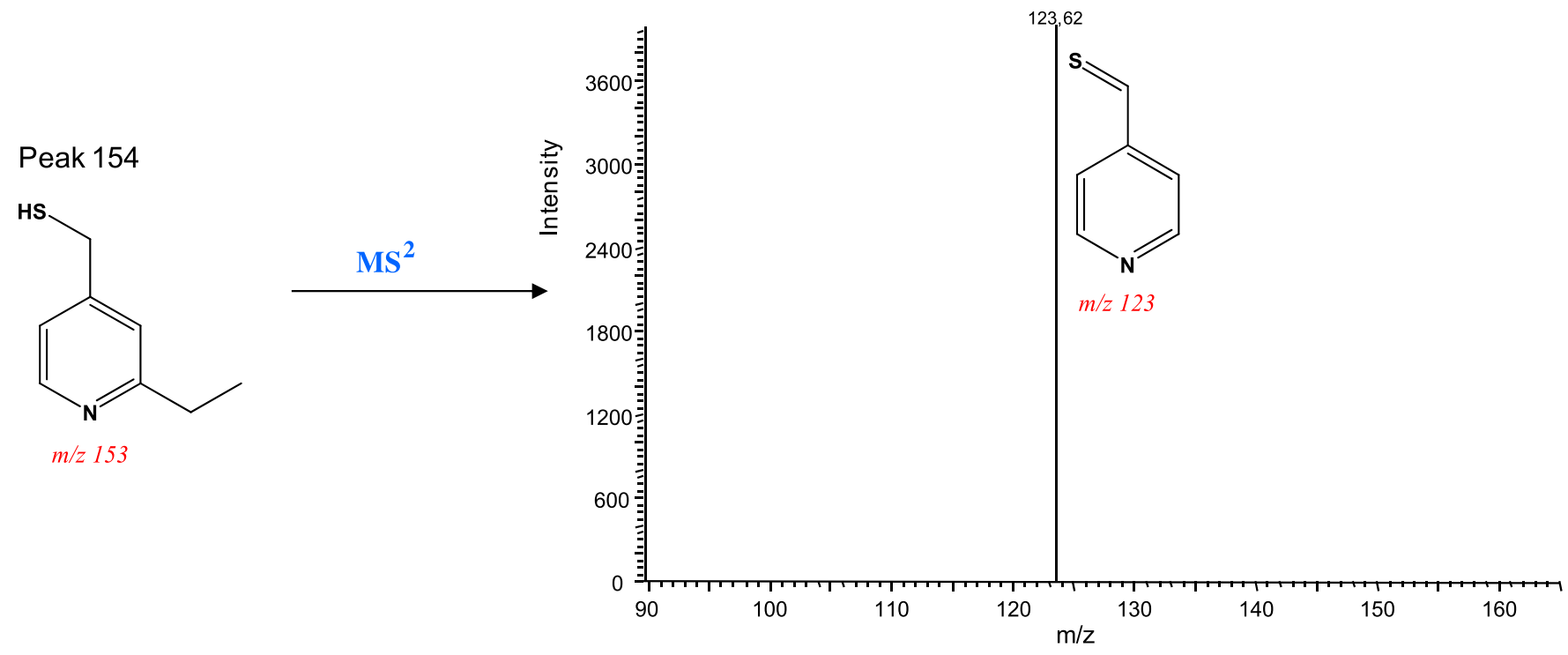

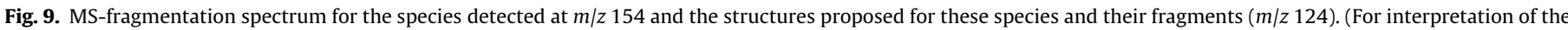
references to color in this figure legend, the reader is referred to the web version of this article.)

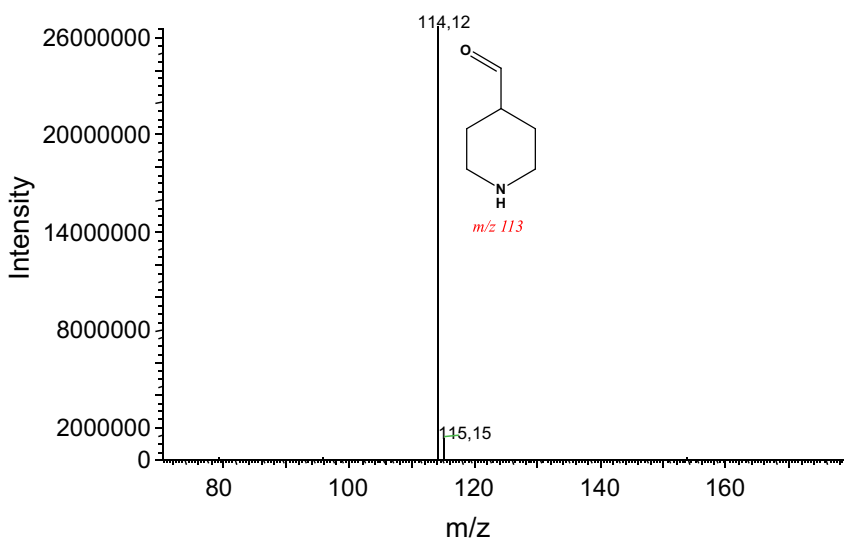

Fig. 10. MS fragmentation spectrum of the specie detected at $\mathrm{m} / \mathrm{z} 227$. (For interpretation of the references to color in this figure legend, the reader is referred to the web version of this article.)

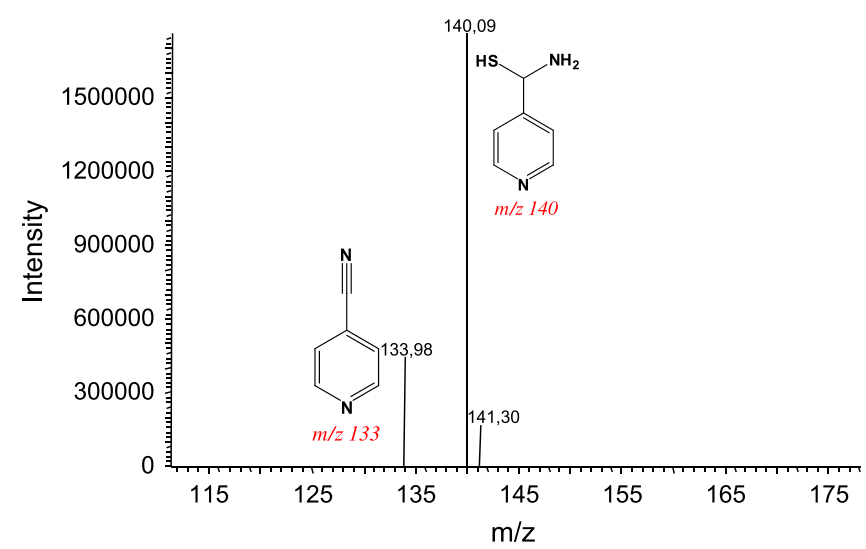

Fig. 11. $M S^{2}$ spectrum of pure ETA. (For interpretation of the references to color in this figure legend, the reader is referred to the web version of this article.)

may lead to high local drug concentrations, and even supersaturation, thus increasing the net absorption and respective drug permeation $[32,46]$.

\subsection{Metabolization of ETA in HepG2 cells}

Most of the literature on the subject reports that ETA must be activated before hitting its cellular target [47], through $S$-oxidation. Though ETA can be oxidized to its sulfoxide (ETA-SO, 2) in the liver, it has been suggested that the drug is mainly activated by the pathogen itself $[7,14,16,48]$. Thus, ETA seems to be mainly activated by the mycobacterial enzyme, EtaA, a flavin-containing monooxygenase, via an unstable, doubly oxidized, sulfinate intermediate $\mathbf{3}$; this reactive intermediate undergoes further conversions to finally yield 2-ethyl-4-amidopyridine, 4, possibly via the nitrile intermediate $\mathbf{5}$.

In the present study, we performed a comparative analysis of ETA metabolic degradation within HepG2 cells, using both the free drug and drug-loaded TCPSi microparticles. Although HepG2 cells lack some liver enzymes, and obviously mycobacterial enzymes as well, they provide a simple medium to test the effect of the particles on the drug metabolic degradability.

In order to identify the metabolites formed under the conditions employed, an LC-ESI/MS study was undertaken, using samples of both free and loaded drug after incubation with HepG2 cells for $100 \mathrm{~min}$. Fig. 6 shows the results from incubation of free ETA. Two major bands where observed in the chromatogram: the first was eluted at ca. $10 \mathrm{~min}$ and the second at ca. $11 \mathrm{~min}$. MS analysis of the eluted bands allowed to ascribe the first band to undegraded ETA $\left(\mathrm{m} / \mathrm{z}\right.$ of ETA's quasi-molecular ion, $[\mathrm{M}+\mathrm{H}]^{+} \approx$ 167), whereas the second band was associated to a set of three metabolites with $m / z$ of 114,154 , and 226 .

Fig. 7 shows the chromatogram and mass spectra obtained in the LC-ESI/MS analysis of ETA degradation after 100-min incubation of ETA-loaded TCPSi microparticles with HepG2 cells. Comparing the chromatogram obtained in this analysis (Fig. 7, top) with that previously shown for the incubation of free ETA (Fig. 6, top), it is clear that ETA metabolization is substantially more extensive when the drug is loaded into the TCPSi microparticles when compared to free drug: the ETA peak eluted at ca. $10 \mathrm{~min}$ is practically undetectable in the chromatogram shown in Fig. 7 (top). In turn, the band eluted at ca. $11 \mathrm{~min}$ is prominent and again associated to three species with $m / z$ of 114,154 , and 227.

A preliminary structural identification of the three species arising from ETA incubation with HepG2 cells was undertaken by 
(A)

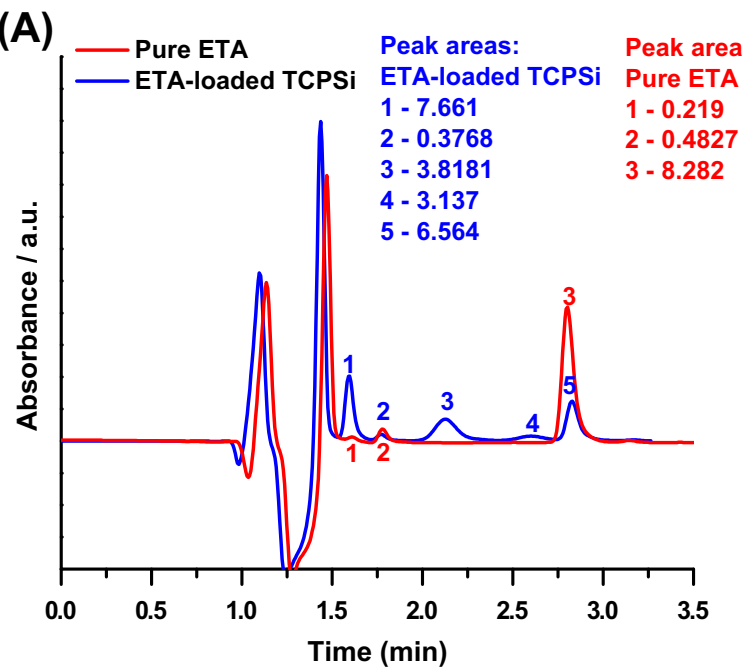

(B)

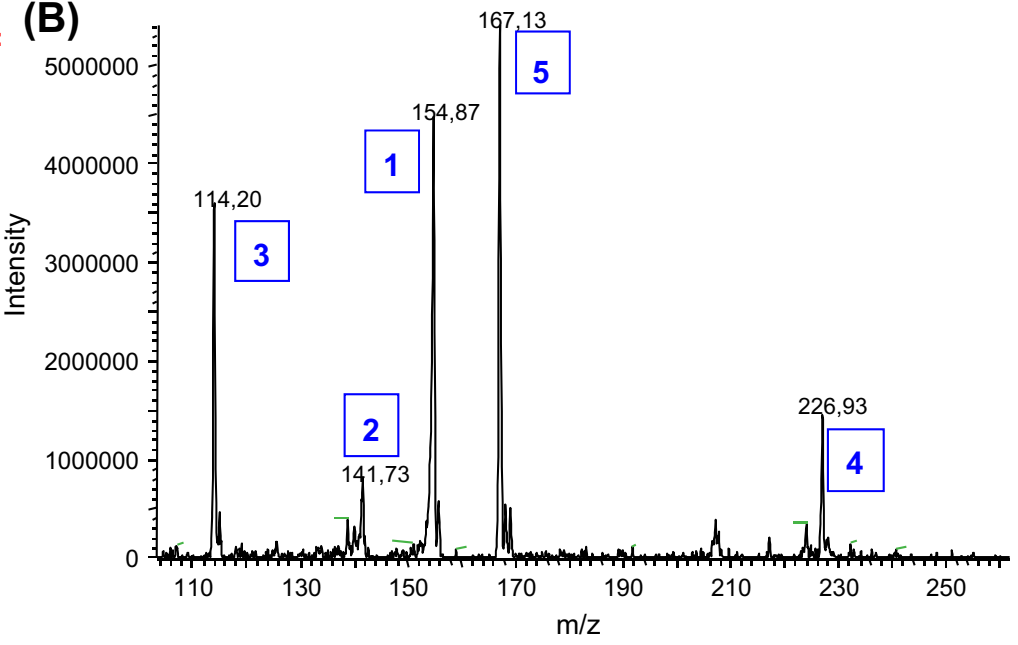

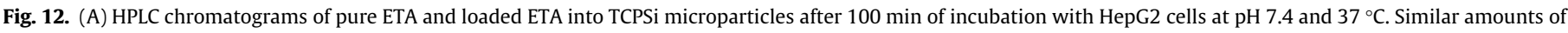

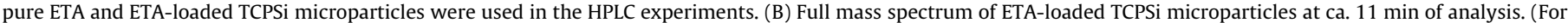
interpretation of the references to color in this figure legend, the reader is referred to the web version of this article.)

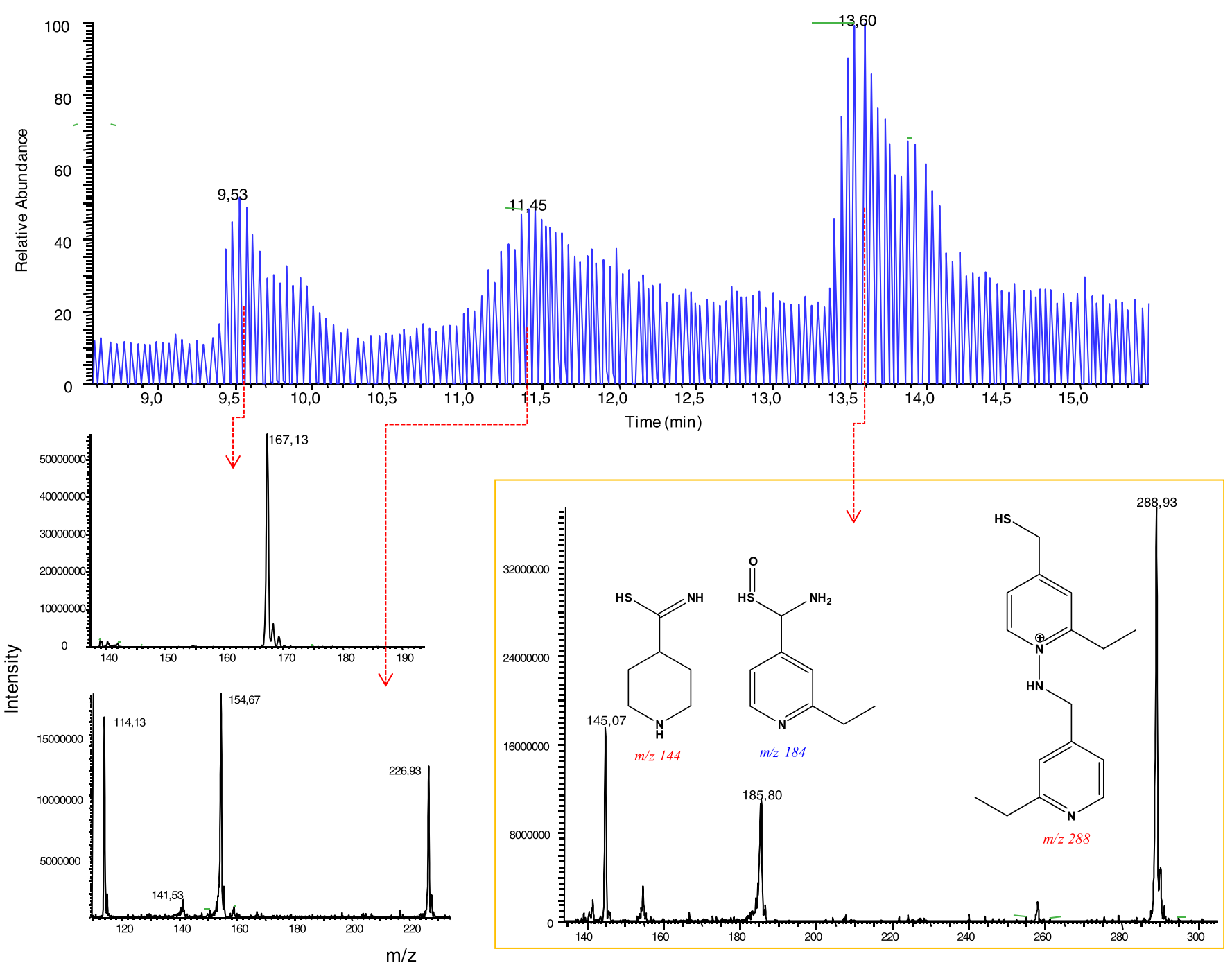

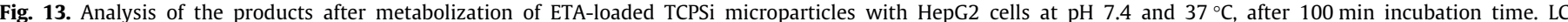

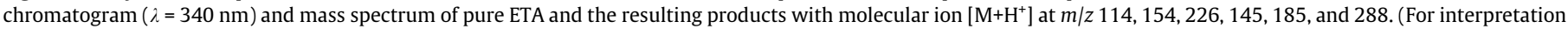
of the references to color in this figure legend, the reader is referred to the web version of this article.) 
tandem-MS (MS ${ }^{2}$ ) analysis. Fig. 8 shows the fragmentation spectrum obtained for the species detected at $m / z 114$ that is proposed to correspond to the quasi-molecular ion of 4-formylpiperazine, which is compatible with its fragmentation to the molecular ion of pyridine $(\mathrm{m} / \mathrm{z} 79)$ and the quasi-molecular ion of 4-methyl1,4-dihydropyridine.

Similarly, Fig. 9 shows the fragmentation suffered by the species detected at $m / z 154$, which is proposed to be 2-ethyl-4-mercaptomethylpyridine, which is compatible with the quasi-molecular ion of 4-thioformylpyridine at $m / z \sim 124$.

Finally, it was postulated that the species detected at $m / z 227$ was the quasi-molecular ion of a 4-formylpiperazine $(\mathrm{m} / \mathrm{z} 113) \mathrm{di}$ mer, which was supported by the fragmentation spectrum obtained for that species and where the only fragment was detected at $m / z \sim 114$ (Fig. 10).

To provide proof that the species observed in the MS study above did arise from ETA incubation with HepG2 cells, and not from fragmentation of the drug in the course of MS analysis, the $\mathrm{MS}^{2}$ spectrum of pure ETA was obtained under identical conditions as the ones described above (Fig. 11).

The results above indicate that ETA is fragmented into minor species detected at $m / z \sim 134$, probably corresponding to the nitrile derivative, similar to $\mathbf{5}$, formerly proposed by Vanneli and coworkers as a possible intermediate of EtaA-mediated metabolism of ETA [16]. The absence of C-2 ethyl group was also reported by the same authors for the analogues of ETA that are oxidized by the purified flavoprotein. The major fragment, however, was detected at $m / z 140$, possibly corresponding to the molecular ion of aminomercaptomethylpyridine, that is, the reduced thiol derivative of desethyl-ETA.

Interestingly, the amount of pure ETA converted into its metabolites after 100 min was very low. In contrast, the ETA loaded into TCPSi microparticles was more extensively metabolized during the same time period, regarding both number and amount of metabolites (see Fig. 12). Although the phenomenon is not fully understood yet, it is probable that the surface chemistry of the TCPSi particles triggered some drug-particle surface reactions inducing metabolite formation of the drug loaded inside the pores [27]. This needs, however, to be confirmed in future studies.

Fig. 12A shows the study of ETA-loaded TCPSi particles after $100 \mathrm{~min}$ (transport experiments). Based on the intensity and profile of HPLC peaks, we postulate that there is a direct relationship between what is observed in HPLC and LC-MS results. The principal compounds (1, 3 and 4) were identified and a peak at $m / z 141$ (2, Fig. 12B) was similar to the principal ion fragment of pure ETA (see Fig. 11). However, it is likely that this compound was formed during the transport experience and not during the analysis by LCESI/MS.

The metabolization of ETA in HepG2 cells (Fig. 13) yielded a new group of compounds at retention time of ca. 13 min (again, at $10 \mathrm{~min}$, it is observed ETA, and at $11 \mathrm{~min}$, it is observed the three metabolites identified in Figs. 8-10). In this area, it is possible to observe the metabolite ETA-SO $(\mathbf{2}, m / z 185)$ and two other, corresponding to the new structures $(\mathrm{m} / z 288$ and $\mathrm{m} / \mathrm{z} 144)$. However, it was not possible to fragment these three compounds, although we assume that there is a relationship between the structures proposed for the other two new compounds of the parent drug at the retention time of ca. $11 \mathrm{~min}$.

\section{Conclusions}

In the present work, we have loaded ETA into TCPSi microparticles and studied the solubility, toxicity, permeability, and metabolic profiles of ETA loaded into the particles. The physicochemical and metabolic properties of the anti-tubercular drug
ETA were favorably modulated by loading the drug into the TCPSi microparticles. The solubility and permeability of ETA was clearly enhanced after loaded into TCPSi particles at different $\mathrm{pH}$-values. ETA was in general toxic at concentrations above $0.50 \mathrm{mM}$ to HepG2, Caco-2, and RAW macrophage cells, but the toxicity was drastically reduced when the drug was loaded into the microparticles. ETA showed a fast metabolization process in the presence of the TCPSi particles possibly triggered by the drug-surface particle interactions. New thiolated metabolites were identified from incubation of ETA-loaded TCPSi microparticles with HepG2 liver cells, which is relevant for the future development of ETA derivatives with improved therapeutic action and reduced propensity to elicit resistance by Mycobacteria.

\section{Acknowledgments}

H.A. Santos acknowledges financial support from the Academy of Finland (decision numbers 127099, 252215 and 256394) and the University of Helsinki Research Funds (Grant No. 490039). N. Vale thanks Portuguese Foundation for Science and Technology (FCT) for financial support through Post-Doc Grant SFRH/BPD/ 48345/2008 and CONC-REEQ/275/QUI.

\section{References}

[1] D. Laurenzo, S.A. Mousa, Mechanisms of drug resistance in Mycobacterium tuberculosis and current status of rapid molecular diagnostic testing, Acta Trop. 119 (2011) 5-10.

[2] US Centers for Disease Control and Prevention, Atlanta. <http://www.cdc.gov/> (accessed 13.10.11)

[3] Y. Zhang, W.W. Yew, Mechanisms of drug resistance in Mycobacterium tuberculosis, Int. J. Tuberc. Lung Dis. 13 (2009) 1320-1330.

[4] R. Long, Drug-resistant tuberculosis, Can. Med. Assoc. J. 163 (2000) 425-428.

[5] A. Banerjee, E. Dubnau, A. Quemard, V. Balasubramanian, K.S. Um, T. Wilson, D. Collins, G. Lisle, W.R. Jacob, InhA, a gene encoding a target for isoniazid and ethionamide in Mycobacterium tuberculosis, Science 263 (1994) 227-230.

[6] K. Johnsson, D.S. King, P.G. Schultz, Studies on the mechanism of action of isoniazid and ethionamide in the chemotherapy of tuberculosis, J. Am. Chem. Soc. 117 (1995) 5009-5010.

[7] A. Baulard, J.C. Betts, J. Engohang-Ndong, S. Quan, R.A. McAdam, P.J. Brennan, C. Locht, G.S. Besra, Activation of the pro-drug ethionamide is regulated in mycobacteria, J. Biol. Chem. 275 (2000) 28326-28331.

[8] A.A. Francois, C.R. Nishida, P.O. Montellano, I.R. Phillips, E.A. Shephard, Human flavin-containing monooxygenase 2.1 catalyzes oxygenation of the antitubercular drugs thiacetazone and ethionamide, Drug Metab. Disp. 37 (2009) 178-186.

[9] J.P. Johnston, P.O. Kane, M.R. Kibby, The metabolism of ethionamide and its sulphoxide, J. Pharm. Pharmacol. 19 (1967) 1-9.

[10] C. Vilchèze, T.R. Weisbrod, B. Clen, L. Kremer, M.H. Hazbón, F. Wang, D. Alland, J.C. Sacchettini, W.J. Jacobs, Altered NADH/NAD ${ }^{+}$ratio mediates coresistance to isoniazid and ethionamide in mycobacteria, Antimicrob. Agents Chemother. 49 (2005) 708-720.

[11] A.G. Dodge, J.E. Richman, G. Johnson, L.P. Wackett, Metabolism of thioamides by Ralstonia pickettii TA. Appl. Environ. Microbiol. 72 (2006) 7468-7476.

[12] L.G. Dover, A. Alahari, P. Gratraud, J.M. Gomes, V. Bhowruth, R.C. Reynolds, G.S. Besra, L. Kremer, EthA, a common activator of thiocarbamide-containing drugs acting on different mycobacterial targets, Antimicrob. Agents Chemother. 51 (2007) 1055-1063.

[13] X. Hanoulle, J.M. Wieruszeski, P. Rousselot-Pailley, I. Landrieu, C. Locht, G. Lippens, A.R. Baulard, Selective intracellular accumulation of the major metabolite issued from the activation of the prodrug ethonamide in mycobacteria, J. Antimicrob. Chemother. 58 (2006) 768-772.

[14] X. Hanoulle, J.M. Wieruszeski, P. Rousselot-Pailley, I. Landrieu, A.R. Baulard, G. Lippens, Monitoring of the ethionamide pro-drug activation in mycobacteria by ${ }^{1} \mathrm{H}$ high resolution magic angle spinning NMR, Biochem. Biophys Res. Commun. 331 (2005) 452-458.

[15] P.J. Jenner, G.A. Ellard, P.J.K. Gruer, V.R. Aber, A comparison of the blood levels and urinary excretion of ethionamide and prothionamide in man, $J$. Antimicrob. Chemother. 13 (1984) 267-277.

[16] T.A. Vanneli, A. Dykman, P.R.O. Montellano, The antituberculosis drug ethionamide is activated by a flavoprotein monooxygenase, J. Biol. Chem. 277 (2002) 12824-12829.

[17] M.H. Cynamon, M. Sklaney, Gatifloxacin and ethionamide as the foundation for therapy of tuberculosis, Antimicrob. Agents Chemother. 47 (2003) 2442-2444.

[18] B. Auclair, D.E. Nix, R.D. Adam, G.T. James, C.A. Peloquin, Pharmacokinetics of ethionamide administered under fasting conditions or with orange juice, food or antacids, Antimicrob. Agents Chemother. 45 (2001) 810-814. 
[19] M. Zhu, R. Namdar, J.J. Stambaugh, J.R. Starke, A.E. Bulpitt, S.E. Berning, C.A Peloqun, Population pharmacokinetics of ethionamide in patients with tuberculosis, Tuberculosis 82 (2002) 91-96.

[20] S.H. Cardoso, M.V. Almeida, J.V.A. Assis, R. Diniz, N.L. Speziali, M.V.N. Sousa, Synthesis and characterization of $n$-hydroxyalkyl and oxazolinyl ethionamide derivatives, J. Sulfur Chem. 29 (2008) 145-149.

[21] E. Lopes, A.R. Pohlmann, V. Bassani, S.S. Guterres, Polymeric colloidal systems containing ethionamide: preparation and physic-chemical characterization, Pharmazie 77 (2000) 527-530.

[22] J.T. Santini Jr, M.J. Cima, R.A. Langer, A controlled-release microchip, Nature 397 (1999) 335-338.

[23] V.S. Lin, K. Motesharei, K.P. Dancil, M.J. Sailor, M.R. Ghadiri, A porous siliconbased optical interferometric biosensor, Science 278 (1997) 840-843.

[24] F. Wang, H. Hui, T.J. Barnes, C. Barnett, C.A. Prestidge, Oxidized mesoporous silicon microparticles for improved oral delivery of poorly soluble drugs, Mol. Pharm. 7 (2010) 227-236.

[25] J. Salonen, L. Laitinen, A.M. Kaukonen, J. Tuura, M. Bjorkqvist, T. Heikkila, K. Vaha-Heikkila, J. Hirvonen, V.P. Lehto, Mesoporous silicon microparticles for oral drug delivery: loading and release of five model drugs, J. Control. Release 108 (2005) 362-374.

[26] L.M. Bimbo, E. Makila, T. Laaksonen, V.P. Lehto, J. Salonen, J. Hirvonen, H.A. Santos, Drug permeation across intestinal epithelial cells using porous silicon nanoparticles, Biomaterials 32 (2011) 2625-2633.

[27] P. Kinnari, E. Makila, T. Heikkila, J. Salonen, J. Hirvonen, H.A. Santos, Comparison of mesoporous silicon and non-ordered mesoporous silica materials as drug carriers for itraconazole, Int. J. Pharm. 414 (2011) 148-156.

[28] M. Tahvanainen, T. Rotko, E. Mäkilä, H.S. Santos, D. Neves, D.T. Laaksonen, A. Kallonen, K. Hämäläinen, M. Peura, R. Serimaa, J. Salonen, J. Hirvonen, L. Peltonen, Tablet preformulations of indomethacin-loaded mesoporous silicon microparticles, Int. J. Pharm. 422 (2012) 125-131.

[29] E.J. Anglin, L. Cheng, W.R. Freeman, M.J. Sailor, Porous silicon in drug delivery devices and materials, Adv. Drug Deliv. Rev. 60 (2008) 1266-1277.

[30] J. Salonen, A.M. Kaukonen, J. Hirvonen, V.P. Lehto, Mesoporous silicon in drug delivery applications, J. Pharm. Sci. 97 (2008) 632-653.

[31] H.A. Santos, L.M. Bimbo, V.P. Lehto, A.J. Airaksinen, J. Salonen, J. Hirvonen, Multifunctional porous silicon for therapeutic drug delivery and imaging, Curr. Drug Discov. Technol. 8 (2011) 228-249.

[32] A.M. Kaukonen, L. Laitinen, J. Salonen, J. Tuura, T. Heikkilä, T. Limnell, J. Hirvonen, V.-P. Letho, Enhanced in vitro permeation of furosemide loaded into thermally carbonized mesoporous silicon (TPCSi) microparticles, Eur. J. Pharm. Biopharm. 66 (2007) 348-356.

[33] L.M. Bimbo, M. Sarparanta, H.A. Santos, A.J. Airaksinen, E. Makila, T. Laaksonen, L. Peltonen, V.P. Lehto, J. Hirvonen, J. Salonen, Biocompatibility of thermally hydrocarbonized porous silicon nanoparticles and their biodistribution in rats, ACS Nano 4 (2010) 3023-3032.

[34] M. Sarparanta, E. Mäkilä, T. Heikkilä, J. Salonen, E. Kukk, V.-P. Lehto, H.A. Santos, J. Hirvonen, A.J. Airaksinen, 18F-labeled modified porous silicon particles for investigation of drug delivery carrier distribution in vivo with positron emission tomography, Mol. Pharm. 8 (2011) 1799-1806.
[35] J.H. Park, L. Gu, G. von Maltzahn, E. Ruoslahti, S.N. Bhatia, M.J. Sailor, Biodegradable luminescent porous silicon nanoparticles for in vivo applications, Nat. Mater. 8 (2009) 331-336.

[36] H.A. Santos, J. Riikonen, J. Salonen, E. Mäkilä, T. Heikkilä, T. Laaksonen, L. Peltonen, V.-P. Letho, J. Hirvonen, In vitro cytotoxicity of porous silicon microparticles: effect of the particle concentration, surface chemistry and size, Acta Biomater. 6 (2010) 2721-2731.

[37] L.M. Bimbo, E. Mäkilä, J. Raula, T. Laaksonen, P. Laaksonen, K. Strommer, E.I Kauppinen, J. Salonen, M.B. Linder, J. Hirvonen, H.A. Santos, Functional hydrophobin-coating of thermally hydrocarbonized porous silicon microparticles, Biomaterials 32 (2011) 9089-9099.

[38] M. Kilpelainen, J. Riikonen, M.A. Vlasova, A. Huotari, V.-P. Lehto, J. Salonen, K.H. Herzig, K. Jarvinen, In vivo delivery of a peptide, ghrelin antagonist, with mesoporous silicon microparticles, J. Control. Release 137 (2009) 166-170.

[39] M. Kilpelainen, J. Monkare, M.A. Vlasova, J. Riikonen, V.-P. Lehto, J. Salonen, K. Jarvinen, K.H. Herzig, Nanostructured porous silicon microparticles enable sustained peptide (Melanotan II) delivery, Eur. J. Pharm. Biopharm. 77 (2011) 20-25.

[40] T. Tanaka, L.S. Mangala, P.E. Vivas-Mejia, R. Nieves-Alicea, A.P. Mann, E. Mora, H.D. Han, M.M.K. Shahzad, X.W. Liu, R. Bhavane, J.H. Gu, J.R. Fakhoury, C. Chiappini, C.H. Lu, K. Matsuo, B. Godin, R.L. Stone, A.M. Nick, G. LopezBerestein, A.K. Sood, M. Ferrari, Sustained small interfering RNA delivery by mesoporous silicon particles, Cancer Res. 70 (2010) 3687-3696.

[41] T. Laaksonen, H.A. Santos, J. Salonen, J. Riikonen, T. Heikkilä, L. Peltonen, N. Kumar, D.Y. Murzin, V.-P. Letho, Failure of MTT as a toxicity testing agent for mesoporous silicon microparticles, Chem. Res. Toxicol. 20 (2007) 19131918.

[42] E.P. Barrett, L.G. Joyner, P.P. Halenda, The determination of pore volume and area distributions in porous substances. I. Computations from nitrogen isotherms, J. Am. Chem. Soc. 73 (1951) 373-380.

[43] S. Brunauer, P.H. Emmett, E. Teller, Adsorption of gases in multimolecular layers, J. Am. Chem. Soc. 60 (1938) 309-319.

[44] T. Limnell, T. Heikkilä, H.A. Santos, S. Sistonen, S. Hellstén, T. Laaksonen, L. Peltonen, K. Narendra, D.Y. Murzin, M. Louhi-Kultanen, J. Salonen, J. Hirvonen, V.-P. Lehto, Physicochemical stability of high indomethacin payload ordered mesoporous silica MCM-41 and SBA-15 microparticles, Int. J. Pharm. 416 (2011) 242-251.

[45] K.A. Youdim, A. Avdeef, N.J. Abbott, In vitro trans-monolayer permeability calculations: often forgotten assumptions, Drug Discov. Today 21 (2003) 9971003.

[46] J. Brouwers, M.E. Brewster, P. Augustijns, Supersaturating drug delivery systems: the answer to solubility-limited oral bioavailability?, J Pharm. Sci. 98 (2009) 2549-2572.

[47] A.E. DeBarher, K. Mdluli, M. Bosman, L.G. Bekker, C.E. Barry, Ethionamide activation and sensitivity in multidrug-resistant Mycobacterium tuberculosis, Proc. Natl. Acad. Sci. USA 97 (2000) 9677-9682.

[48] P. Acred, D.M. Brown, The antitubercular properties of a series of thiols and sulphides, Brit. J. Pharmacol. 15 (1960) 485-495. 